\title{
Subunit composition of seed storage proteins in high-protein soybean genotypes
}

\author{
Ksenija Taski-Ajdukovic(1), Vuk Djordjevic ${ }^{(1)}$, Milos Vidic $^{(1)}$ and Milka Vujakovic ${ }^{(1)}$ \\ (1)Institute for Field and Vegetable Crops, Maksima Gorkog 30, 21000, Novi Sad, Serbia. E-mail: ksenijat@ifvcns.ns.ac.rs, vuk@ifvcns.ns.ac.rs, \\ vidicmilos@ifvcns.ns.ac.rs, milka.vujakovic@ifvcns.ns.ac.rs
}

\begin{abstract}
The objective of this work was to quantify the accumulation of the major seed storage protein subunits, $\beta$-conglycinin and glycinin, and how they influence yield and protein and oil contents in high-protein soybean genotypes. The relative accumulation of subunits was calculated by scanning SDS-PAGE gels using densitometry. The protein content of the tested genotypes was higher than control cultivar in the same maturity group. Several genotypes with improved protein content and with unchanged yield or oil content were developed as a result of new breeding initiatives. This research confirmed that high-protein cultivars accumulate higher amounts of glycinin and $\beta$-conglycinin. Genotypes KO5427, KO5428, and KO5429, which accumulated lower quantities of all subunits of glycinin and $\beta$-conglycinin, were the only exceptions. Attention should be given to genotypes KO5314 and KO5317, which accumulated significantly higher amounts of both subunits of glycinin, and to genotypes KO5425, KO5319, KO539 and KO536, which accumulated significantly higher amounts of $\beta$-conglycinin subunits. These findings suggest that some of the tested genotypes could be beneficial in different breeding programs aimed at the production of agronomically viable plants, yielding high-protein seed with specific composition of storage proteins for specific food applications.
\end{abstract}

Index terms: Glycine max, $\beta$-conglycinin, glycinin, protein content, subunit composition.

\section{Composição de subunidades de proteínas de reserva em genótipos de soja com alto teor de proteína}

\begin{abstract}
Resumo - O objetivo deste trabalho foi quantificar o acúmulo das principais subunidades de proteínas de reserva da soja, $\beta$-conglicinina e glicinina, e como elas influenciam a produtividade e os conteúdos de proteína e de óleo em genótipos de soja com alto conteúdo de proteína. A acumulação relativa de subunidades foi calculada por escaneamento em géis SDS-PAGE, com uso de densitometria. O conteúdo de proteínas dos genótipos testados foi maior que o da cultivar controle dentro do mesmo grupo de maturação. Vários genótipos com conteúdo de proteína aumentado, mas com produtividade ou conteúdo de óleo inalterados, foram desenvolvidos como resultados de novas iniciativas de melhoramento. Esta pesquisa confirmou que as cultivares com alto conteúdo de proteína acumulam maior quantidade de glicinina e $\beta$-conglicinina. Os genótipos KO5427, KO5428, e KO5429, que acumularam menor quantidade de todas as subunidades de glicinina e $\beta$-conglicinina, foram as únicas exceções. Deve-se atentar para os genótipos KO5314 e KO5317, que acumularam quantidades significativamente maiores das duas subunidades da glicinina, e para os genótipos KO5425, KO539 e KO536, que acumularam quantidades significativamente maiores das subunidades de $\beta$-conglicinina. Estes resultados indicam que alguns dos genótipos testados poderiam ser benéficos em programas de melhoramento que visem à produção de plantas agronomicamente viáveis, com sementes com alto conteúdo de proteínas e composição específica de proteínas de reserva para fins alimentícios definidos.
\end{abstract}

Termos para indexação: Glycine max, $\beta$-conglicinina, glicinina, conteúdo de proteína, composição das subunidades.

\section{Introduction}

Soybean [Glycine $\max$ L. (Merr.)] is an important source of edible vegetable oil and protein throughout the world and is used in a multitude of food and industrial applications. Seeds of the most commercially grown soybean cultivars contain an average of $360-380 \mathrm{~g} \mathrm{~kg}^{-1}$ protein and $190 \mathrm{~g} \mathrm{~kg}^{-1}$ oil; however, both genetic and environmental factors strongly influence seed composition (Brumm \& Hurburgh Junior, 2002; Zarkadas et al., 2007). More recently, soybean genotypes have been bred to increase seed yield and oil content, since they are mainly used for refined oil for human consumption, while 
protein meal is mainly used as a source of protein for animal husbandry. With the current increase in meat consumption, the demand for protein in animal husbandry has increased. A major impediment to increasing soybean protein through selective breeding lies in the negative correlation between protein content and yield, on one hand, and oil content and yield on the other (Burton, 1987). Nevertheless, soybean breeders have made notable progress in overcoming that negative correlation and have developed agronomically viable high protein cultivars (Cober \& Voldeng, 2000; Wilcox, 2001).

Soybean storage proteins have two major fractions, $\beta$-conglycinin (7S) and glycinin (11S), accounting for approximately $70 \%$ of the total proteins. Glycinin accounts for about $60 \%$ of storage proteins and $\beta$-conglycinin for the remaining $40 \%$. $\beta$-conglycinin is a glycoprotein with molecular weight of $150-175 \times 10^{3}$, and is formed by various combinations of three nonidentical but homologous polypeptide subunits ( $\alpha, \alpha$ and $\beta$ ) (Thanh \& Shibasaki, 1978). Glycinin is a hexamer with a molecular weight between 320-375 x 103. Each subunit consists of an acidic and a basic polypeptide linked by a disulfide bond (Mori et al., 1981).

The major storage proteins do not contain many sulphur aminoacids, although glycinin contains more (3 to $4.5 \%$ ) than $\beta$-conglycinin (less than $1 \%)$. Humans and monogastric animals are unable to synthesize sulphur amino acids, and it has been shown that soybean proteins do not provide adequate sulphur amino acids to meet the dietary requirements. As soybean is widely used in animal feeding, and its consumption by humans gradually increases due to the beneficial effect of soybean on human health, improvement of the nutritive value of the globulin ratio in soybean seed became very important. In addition, the functional properties of soybean proteins, as emulsifying or foaming agents for food formulation, are limited by the globular structure of glycinin (Poysa et al., 2006). Such findings provide an opportunity for soybean breeders to develop genotypes with specific protein compositions for specific food applications.

The objective of the present work was to estimate the accumulation of the main seed storage protein subunits, glycinin and $\beta$-conglycinin, among high-protein soybean genotypes, and to determine whether these genotypes preferentially accumulate specific polypeptides and how this influences the yield and the protein and oil contents in different maturity groups.

\section{Materials and Methods}

Forty soybean genotypes developed at the Institute for Field and Vegetable Crops in Novi Sad, Serbia, were used in the study. The genotypes belonged to maturity groups 0, I, II and III. Each of the groups was represented by nine newly developed high-protein genotypes and one commercially grown cultivar. A commercial cultivar from each appropriate maturity group (with average protein content for high-yielding genotypes) was used as control. Two-year trials were carried out at Institute's experimental fields in Rimski Sancevi. The dominant soil type was calcareous Chernozem with a $\mathrm{pH}$ of 7.65 and organic matter content of $3.3 \%$. Field trials were carried out in a completely randomized design, with three replicates and four rows $(4 \mathrm{~m})$ per genotype, with 0.45 -m spacing between rows. Standard agronomic practices were followed.

Protein and oil content were determined by near-infrared reflectance (NIR) spectroscopy, using PERTEN DA 7000 (Perten, Stockholm, Sweden), with a sample of $250 \mathrm{~g}$ of intact soybean seeds. Protein and oil contents were calculated on dry basis.

Soybean seeds were ground in a Thermomix, Worwerk (The Pinehill Partnership Ltd., Berkshire, England). Forty milligrams of seed powder were extracted in $1 \mathrm{~mL}$ of extraction buffer $\left(0.03 \mathrm{~mol} \mathrm{~L}^{-1}\right.$ Tris- $\mathrm{HCl} \quad \mathrm{pH} \quad 8.0$ containing $0.01 \quad \mathrm{~mol} \mathrm{~L}^{-1}$ $\beta$-mercaptoethanol). The samples were left for one hour at room temperature with rotation every $10 \mathrm{~min}$. The samples were then centrifuged for $20 \mathrm{~min}$ at $11 \times 10^{3} \mathrm{~g}$ at room temperature. The soluble protein concentration in the supernatant was analyzed according to the Bradford method (Bradford, 1976) with bovine serum albumin (BSA) as standard.

Electrophoresis SDS-PAGE was carried out according to the standard procedure (Laemmli, 1970) in $1.5 \mathrm{~mm}$ thick gels with $12.5 \%(\mathrm{w} / \mathrm{v})$ separating gel and $5 \%(\mathrm{w} / \mathrm{v})$ stacking gel in a vertical electrophoresis unit (Carl Roth $\mathrm{GmbH}$, Karlsruhe, Germany). In one of the outside wells of each gel, molecular weight standards - Wide Molecular Weight Range SigmaMarkers, (Sigma-Aldrich Chemie GmbH, Steinheim, Germany) were run. These markers were 
used to estimate the molecular weight ranges of polypeptides and to identify the subunits of the major soybean proteins. The last two wells at the opposite end of each gel contained proteins from the soybean cultivar Vojvodjanka, used for comparison and ratio calculations. Samples of the specific soybean genotypes were loaded in the remaining inside wells. Fifty microliters of the extract were mixed with $50 \mu \mathrm{L}$ of SDS-sample buffer $\left(0.15 \mathrm{~mol} \mathrm{~L}^{-1}\right.$ TRIS-HCl, $\mathrm{pH}$ $6.8,3 \% \mathrm{w} / \mathrm{v}$ SDS, $5 \% \mathrm{v} / \mathrm{v} \beta$-mercaptoethanol, $7 \% \mathrm{v} / \mathrm{v}$ glycerol and $0.03 \%$ bromphenol blue) and heated for 3 min in a boiling water bath. The solution was cooled to room temperature and $15 \mu \mathrm{L}$ of the sample was loaded onto each well. SDS-PAGE was carried out at $25 \mathrm{~mA}$ per gel until the tracking dye had migrated through the stacking gel and, then, at $45 \mathrm{~mA}$ per gel until the bromphenol blue was at the bottom of the gel. The temperature of $15-20^{\circ} \mathrm{C}$ was obtained by circulating tap water through the tank buffer. The gels were stained with $0.1 \%$ Coomassie Brilliant Blue R-250 (Sigma-Aldrich GmbH, Steinheim, Germany) in methanol: acetic acid: distilled water (3:1:6) during two hours. When properly stained, gels were destained in the same solution without dye.

The protein bands on the destained gel were quantified using the ImageJ software (Rasband, 2010). In order to quantify the subunits of seed storage proteins, the specified protein band of the tested genotypes was compared to the same protein band of the Vojvodjanka cultivar. The standardized values were then analyzed by pair wise mean comparisons ( $t$ test) for significance between all pairs of genotypes in each maturity group. Principal factor analysis was done using the Statistica 8 (StatSoft, 2010) software. After principal component analysis, factors were rotated by the varimax method.

\section{Results and Discussion}

Protein contents differed significantly in all the soybean genotypes studied in all the maturity groups (Table 1). The protein content of the new soybean genotypes, except for KO5319, in all maturity groups was significantly higher than the protein content in the control cultivar of each maturity group. Genotype KO531 had the highest protein content, with about 90 $\mathrm{g} \mathrm{kg}^{-1}$ more seed protein than the control, followed by genotype $\mathrm{KO} 5427$ with ca. $75 \mathrm{~g} \mathrm{~kg}^{-1}$ seed protein. These results agree with those previously reported by Krishnan (2001) and Poysa et al. (2006). Control genotypes of all maturity groups had the highest oil content, but the oil content of high-protein genotypes was similar to that of commercially grown soybean

Table 1. Yield, protein and oil content of high-protein soybean genotypes and control cultivars ${ }^{(1)}$.

\begin{tabular}{|c|c|c|c|c|}
\hline Genotype & $\begin{array}{c}\text { Yield } \\
\left(\mathrm{kg} \mathrm{ha}^{-1}\right)\end{array}$ & $\begin{array}{l}\text { Seed protein } \\
\left(\mathrm{g} \mathrm{kg}^{-1}\right)\end{array}$ & $\begin{array}{c}\text { Seed oil } \\
\left(\mathrm{g} \mathrm{kg}^{-1}\right)\end{array}$ & $\begin{array}{l}\text { Protein/oil } \\
\text { ratio }\end{array}$ \\
\hline \multicolumn{5}{|c|}{ Maturity group 0} \\
\hline Afrodita & $5393 \pm 123 a$ & $385 \pm 0.6 \mathrm{e}$ & $212 \pm 0.3 \mathrm{a}$ & $1.8 \pm 0.01 \mathrm{~g}$ \\
\hline KO5439 & $3614 \pm 49 d$ & $434 \pm 5.0 \mathrm{a}$ & $174 \pm 4.5 f$ & $2.5 \pm 0.09 \mathrm{a}$ \\
\hline KO5438 & $4334 \pm 93 b$ & $408 \pm 2.3 \mathrm{~d}$ & $192 \pm 2.1 \mathrm{~cd}$ & $2.1 \pm 0.03 \mathrm{~d}$ \\
\hline KO5437 & $3969 \pm 73 c$ & $426 \pm 2.9 \mathrm{~b}$ & $189 \pm 2.5 \mathrm{de}$ & $2.3 \pm 0.04 \mathrm{bc}$ \\
\hline KO5436 & $4468 \pm 139 b$ & $405 \pm 4.2 \mathrm{~d}$ & $1972.0 \pm \mathrm{c}$ & $2.1 \pm 0.04 \mathrm{de}$ \\
\hline KO5435 & $4560 \pm 43 b$ & $419 \pm 2.9 \mathrm{bc}$ & $187 \pm 1.5 \mathrm{de}$ & $2.2 \pm 0.03 \mathrm{c}$ \\
\hline KO5434 & $4546 \pm 128 b$ & $409 \pm 2.1 \mathrm{~d}$ & $209 \pm 1.2 \mathrm{a}$ & $1.9 \pm 0.02 \mathrm{ef}$ \\
\hline KO5433 & $4280 \pm 42 b$ & $435 \pm 2.0 \mathrm{a}$ & $184 \pm 0.9 \mathrm{e}$ & $2.4 \pm 0.02 \mathrm{~b}$ \\
\hline KO5432 & $4517 \pm 110 \mathrm{~b}$ & $404 \pm 1.3 \mathrm{~d}$ & $209 \pm 1.4 \mathrm{ab}$ & $1.9 \pm 0.01 \mathrm{f}$ \\
\hline$\underline{\mathrm{KO} 5431}$ & $4451 \pm 134 b$ & $412 \pm 1.9 \mathrm{~cd}$ & $203 \pm 1.0 \mathrm{~b}$ & $2.0 \pm 0.01 \mathrm{def}$ \\
\hline \multicolumn{5}{|c|}{ Maturity group I } \\
\hline Balkan & $4996 \pm 61 \mathrm{ab}$ & $384 \pm 1.5 \mathrm{~h}$ & $211 \pm 1.5 \mathrm{a}$ & $1.8 \pm 0.02 \mathrm{~g}$ \\
\hline KO5429 & $4496 \pm 55 \mathrm{c}$ & $436 \pm 5.0 \mathrm{~b}$ & $180 \pm 3.0 \mathrm{e}$ & $2.4 \pm 0.06 \mathrm{~b}$ \\
\hline KO5428 & $4597 \pm 45 b c$ & $414 \pm 1.3 \mathrm{ef}$ & $190 \pm 0.6 \mathrm{~d}$ & $2.2 \pm 0.01 \mathrm{de}$ \\
\hline KO5427 & $4528 \pm 151 \mathrm{c}$ & $459 \pm 1.3 \mathrm{a}$ & $158 \pm 0.4 \mathrm{f}$ & $2.9 \pm 0.01 \mathrm{a}$ \\
\hline KO5426 & $4797 \pm 26 a b c$ & $404 \pm 1.9 \mathrm{~g}$ & $192 \pm 1.1 \mathrm{~cd}$ & $2.1 \pm 0.01 \mathrm{def}$ \\
\hline KO5425 & $4403 \pm 241 \mathrm{c}$ & $428 \pm 2.5 c$ & $183 \pm 0.6 \mathrm{e}$ & $2.3 \pm 0.02 \mathrm{c}$ \\
\hline KO5424 & $4998 \pm 174 \mathrm{ab}$ & $407 \pm 2.2 \mathrm{~g}$ & $199 \pm 1.9 b$ & $2.0 \pm 0.03 \mathrm{f}$ \\
\hline KO5423 & $5177 \pm 68 \mathrm{a}$ & $409 \pm 0.7 \mathrm{fg}$ & $195 \pm 0.7 \mathrm{c}$ & $2.1 \pm 0.01 \mathrm{ef}$ \\
\hline KO5422 & $4798 \pm 136 \mathrm{abc}$ & $419 \pm 0.8 \mathrm{de}$ & $192 \pm 0.9 \mathrm{~cd}$ & $2.2 \pm 0.01 \mathrm{~d}$ \\
\hline KO5421 & $4471 \pm 139 c$ & $422 \pm 1.6 \mathrm{~cd}$ & $184 \pm 1.9 \mathrm{e}$ & $2.3 \pm 0.02 \mathrm{c}$ \\
\hline \multicolumn{5}{|c|}{ Maturity group II } \\
\hline Vojvodjank & $5576 \pm 159 a$ & $379 \pm 2.9 \mathrm{e}$ & $211 \pm 1.0 \mathrm{a}$ & $1.8 \pm 0.01 \mathrm{~g}$ \\
\hline KO5319 & $5468 \pm 155 \mathrm{ab}$ & $385 \pm 0.1 \mathrm{e}$ & $208 \pm 1.4 \mathrm{a}$ & $1.8 \pm 0.01 \mathrm{~g}$ \\
\hline KO5318 & $4093 \pm 180 \mathrm{~cd}$ & $441 \pm 4.8 \mathrm{a}$ & $164 \pm 1.2 \mathrm{~g}$ & $2.7 \pm 0.04 \mathrm{~b}$ \\
\hline KO5317 & $4651 \pm 127 \mathrm{bcd}$ & $442 \pm 2.0 \mathrm{a}$ & $157 \pm 1.0 \mathrm{~h}$ & $2.8 \pm 0.02 \mathrm{a}$ \\
\hline KO5316 & $4822 \pm 184 \mathrm{abc}$ & $433 \pm 1.5 b$ & $171 \pm 0.5 f$ & $2.5 \pm 0.01 \mathrm{c}$ \\
\hline KO5315 & $4155 \pm 138 \mathrm{~cd}$ & $441 \pm 1.7 \mathrm{a}$ & $176 \pm 0.3 \mathrm{e}$ & $2.5 \pm 0.01 \mathrm{c}$ \\
\hline KO5314 & $4538 \pm 212 \mathrm{~cd}$ & $433 \pm 1.7 b$ & $180 \pm 0.9 \mathrm{~cd}$ & $2.4 \pm 0.02 \mathrm{~d}$ \\
\hline KO5313 & $4626 \pm 190 \mathrm{~cd}$ & $423 \pm 1.6 \mathrm{c}$ & $183 \pm 1.5 \mathrm{c}$ & $2.3 \pm 0.01 \mathrm{e}$ \\
\hline KO5312 & $4004 \pm 145 d$ & $415 \pm 1.9 \mathrm{~d}$ & $192 \pm 0.6 b$ & $2.2 \pm 0.01 \mathrm{f}$ \\
\hline KO5311 & $4692 \pm 195 \mathrm{bcd}$ & $422 \pm 2.1 \mathrm{c}$ & $178 \pm 0.5 \mathrm{de}$ & $2.4 \pm 0.01 \mathrm{de}$ \\
\hline \multicolumn{5}{|c|}{ Maturity group III } \\
\hline Morava & $5702 \pm 174 a$ & $372 \pm 2.0 \mathrm{f}$ & $220 \pm 1.6 \mathrm{a}$ & $1.7 \pm 0.02 \mathrm{~g}$ \\
\hline KO539 & $4972 \pm 174 \mathrm{abcd}$ & $416 \pm 1.1 \mathrm{de}$ & $191 \pm 0.5 b$ & $2.2 \pm 0.01 \mathrm{ef}$ \\
\hline KO538 & $5057 \pm 194 \mathrm{abc}$ & $413 \pm 1.3 \mathrm{e}$ & $191 \pm 1.6 b$ & $2.1 \pm 0.02 \mathrm{f}$ \\
\hline KO537 & $5360 \pm 131 \mathrm{ab}$ & $421 \pm 0.8 \mathrm{~d}$ & $188 \pm 0.8 \mathrm{~cd}$ & $2.3 \pm 0.01 \mathrm{e}$ \\
\hline KO536 & $4646 \pm 233 \mathrm{bcd}$ & $418 \pm 1.9 \mathrm{de}$ & $191 \pm 1.6 \mathrm{bc}$ & $2.2 \pm 0.02 \mathrm{ef}$ \\
\hline KO535 & $4572 \pm 35 \mathrm{~cd}$ & $436 \pm 3.9 c$ & $185 \pm 1.4 d$ & $2.4 \pm 0.03 \mathrm{~d}$ \\
\hline KO534 & $4885 \pm 194 \mathrm{bcd}$ & $434 \pm 1.0 \mathrm{c}$ & $173 \pm 0.3 \mathrm{e}$ & $2.5 \pm 0.01 \mathrm{c}$ \\
\hline KO533 & $4244 \pm 209 d$ & $451 \pm 0.9 b$ & $160 \pm 0.2 \mathrm{~g}$ & $2.8 \pm 0.01 \mathrm{~b}$ \\
\hline KO532 & $4696 \pm 142 b c d$ & $453 \pm 1.6 b$ & $164 \pm 1.1 \mathrm{f}$ & $2.8 \pm 0.02 b$ \\
\hline KO531 & $4461 \pm 183 \mathrm{~cd}$ & $462 \pm 3.4 \mathrm{a}$ & $157 \pm 1.7 \mathrm{~h}$ & $2.9 \pm 0.05 \mathrm{a}$ \\
\hline
\end{tabular}

${ }^{(1)}$ Mean \pm standard errors followed by equal letters do not differ, at $5 \%$ probability. 
cultivars. Genotypes KO5434, KO5432, and KO5319 remained in the same group as their controls. The oil content varied from 157-220 $\mathrm{g} \mathrm{kg}^{-1}$, which was in accordance with the results obtained by Yaklich (2001) and Poysa et al. (2006) for newly developed high-protein soybean genotypes. The highest protein-to-oil ratio was found in genotypes KO531 and KO5427. Except for KO5319, all new soybean genotypes showed significantly higher ratios than the controls.

Yield of the control cultivars was significantly higher than most of the new soybean genotypes, except for genotypes KO5428, KO5426, KO5424, KO5423 and KO5422, in maturity group I, KO5319 and KO5316, in maturity group II, and KO539, KO538, KO537, in maturity group III, which were similar to the controls for the respective maturity groups (Table 1). All genotypes with unchanged yield, except for KO5319, had improved protein content but lower oil content in comparison to the controls. Genotypes KO5434 and KO5432 were the only ones with improved protein content and unchanged oil content, in comparison to the control, but with lower yield. Therefore, these results confirm the well-documented (Burton, 1987; Helms et al., 1998) negative correlations between protein content, yield and oil content.

Patterns of total soybean proteins of some high-protein soybean varieties and cultivar Vojvodjanka on SDS-polyacrylamide gel are shown in Figure 1. The protein bands were similar among all soybean varieties. On the gel, the 7S protein fraction was separated into $\alpha$ ', $\alpha$ and $\beta$ subunits with molecular weights of approximately $81,000,74,000$ and 50,000 , respectively. The $11 \mathrm{~S}$ protein fraction was separated into acidic and basic subunits. The group of polypeptides near the molecular weight of about 35,000 was a major group of acidic polypeptides.

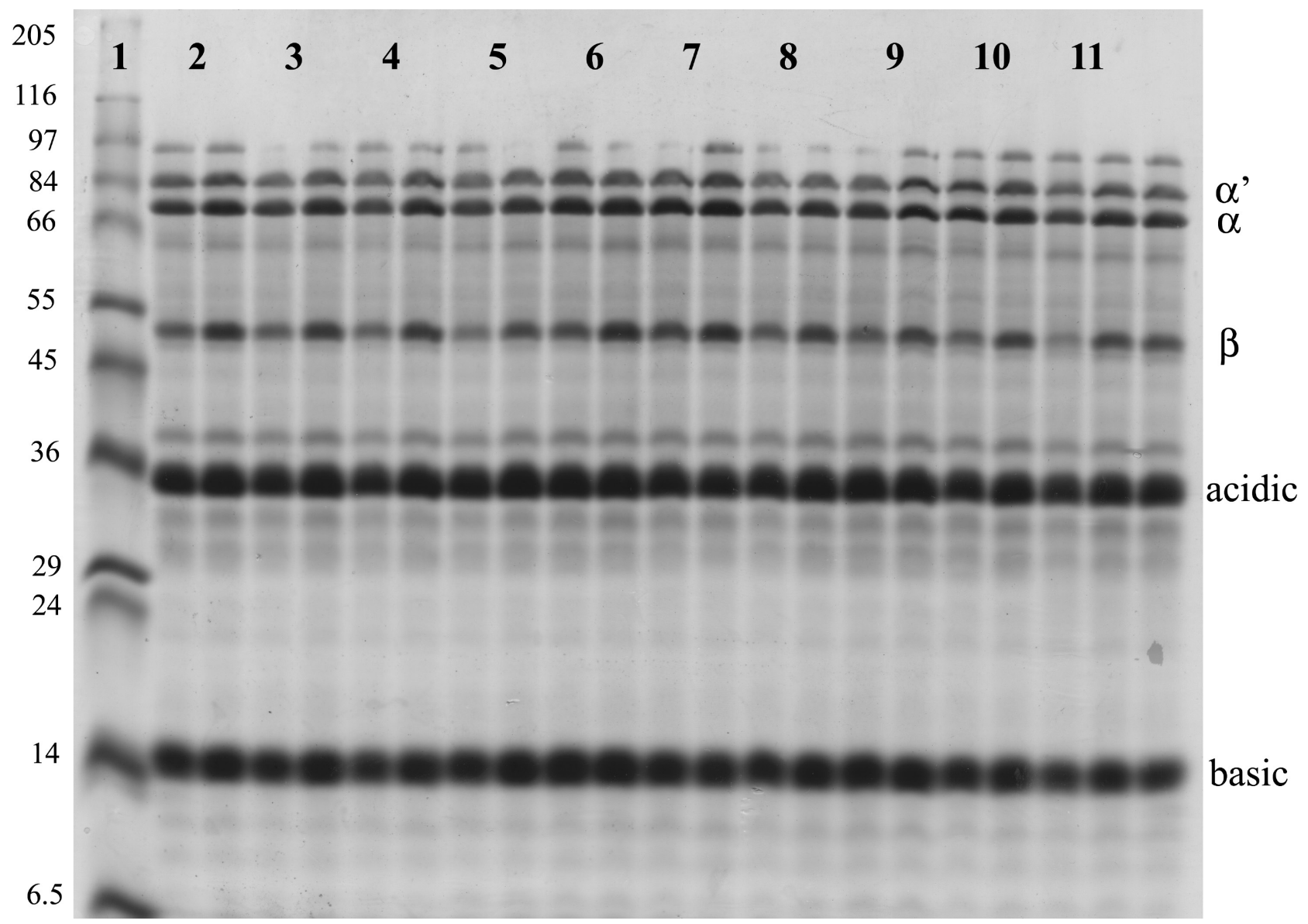

Figure 1. SDS-PAGE gel of the total proteins of high-protein soybean genotypes. 1, molecular weight markers (kDa); 2-10, protein profile of tested soybean genotypes KO5311-KO5319; 11, cultivar Vojvodjanka. 
The group of protein bands with molecular weight values of approximately 14,000 represents the basic components. These results corroborate those reported by other authors (Yaklich, 2001; Zarkadas et al., 2007, Taski-Ajdukovic et al., 2008).
Due to their abundance, $\beta$-conglycinin and glycinin were the main factors responsible for soybean protein quality. The data in Table 2 show that all genotypes of maturity group 0, except for KO5431, contained significantly more of the $\alpha^{\prime}$ and $\alpha$ subunits of

Table 2. Relative expressions of seed storage protein subunits in high-protein soybean genotypes and control cultivars ${ }^{(1)}$.

\begin{tabular}{|c|c|c|c|c|c|}
\hline \multirow[t]{2}{*}{ Genotype } & \multicolumn{3}{|c|}{$\beta$-conglycinin } & \multicolumn{2}{|c|}{ Glycinin } \\
\hline & $\alpha^{\prime}$ & $\alpha$ & $\beta$ & Acidic & Basic \\
\hline \multicolumn{6}{|c|}{ Maturity group 0} \\
\hline Afrodita & $1.2 \pm 0.10 \mathrm{~d}$ & $1.1 \pm 0.02 b$ & $1.6 \pm 0.22 b$ & $1.1 \pm 0.04 \mathrm{e}$ & $1.4 \pm 0.09 \mathrm{f}$ \\
\hline KO5439 & $2.6 \pm 0.24 \mathrm{c}$ & $1.9 \pm 0.15 \mathrm{a}$ & $2.2 \pm 0.29 \mathrm{ab}$ & $1.6 \pm 0.12 \mathrm{a}$ & $2.7 \pm 0.16 \mathrm{de}$ \\
\hline KO5438 & $2.5 \pm 0.07 \mathrm{c}$ & $2.2 \pm 0.14 \mathrm{a}$ & $2.1 \pm 0.19 \mathrm{ab}$ & $1.4 \pm 0.04 b c$ & $2.9 \pm 0.09 \mathrm{bcd}$ \\
\hline KO5437 & $3.2 \pm 0.12 \mathrm{ab}$ & $2.2 \pm 0.06 \mathrm{a}$ & $2.7 \pm 0.13 \mathrm{a}$ & $1.5 \pm 0.06 \mathrm{ab}$ & $3.3 \pm 0.04 \mathrm{a}$ \\
\hline KO5436 & $3.4 \pm 0.20 \mathrm{a}$ & $2.2 \pm 0.06 \mathrm{a}$ & $2.2 \pm 0.12 \mathrm{ab}$ & $1.4 \pm 0.05 b c$ & $3.2 \pm 0.10 \mathrm{abc}$ \\
\hline KO5435 & $3.4 \pm 0.14 \mathrm{a}$ & $2.1 \pm 0.12 \mathrm{a}$ & $2.5 \pm 0.13 \mathrm{a}$ & $1.3 \pm 0.05 b c$ & $2.9 \pm 0.10 \mathrm{bcd}$ \\
\hline KO5434 & $3.1 \pm 0.25 \mathrm{abc}$ & $2.0 \pm 0.10 \mathrm{a}$ & $1.8 \pm 0.20 \mathrm{~b}$ & $1.1 \pm 0.06 \mathrm{de}$ & $2.8 \pm 0.12 \mathrm{cde}$ \\
\hline KO5433 & $2.7 \pm 0.34 \mathrm{bc}$ & $1.9 \pm 0.17 \mathrm{a}$ & $1.7 \pm 0.31 \mathrm{~b}$ & $1.1 \pm 0.06 \mathrm{de}$ & $2.9 \pm 0.19 \mathrm{~cd}$ \\
\hline KO5432 & $2.5 \pm 0.32 \mathrm{c}$ & $1.9 \pm 0.14 \mathrm{a}$ & $1.7 \pm 0.30 \mathrm{~b}$ & $1.3 \pm 0.05 \mathrm{~cd}$ & $3.2 \pm 0.09 \mathrm{ab}$ \\
\hline KO5431 & $1.2 \pm 0.15 \mathrm{~d}$ & $1.3 \pm 0.19 \mathrm{~b}$ & $1.8 \pm 0.26 \mathrm{~b}$ & $1.1 \pm 0.05 \mathrm{e}$ & $2.5 \pm 0.18 \mathrm{e}$ \\
\hline \multicolumn{6}{|c|}{ Maturity group I } \\
\hline Balkan & $1.0 \pm 0.07 \mathrm{e}$ & $0.9 \pm 0.06 \mathrm{~d}$ & $0.9 \pm 0.07 \mathrm{~d}$ & $1.3 \pm 0.10 \mathrm{e}$ & $1.6 \pm 0.07 \mathrm{c}$ \\
\hline KO5429 & $0.7 \pm 0.10 \mathrm{f}$ & $0.7 \pm 0.05 \mathrm{~d}$ & $0.7 \pm 0.05 \mathrm{~d}$ & $1.0 \pm 0.05 \mathrm{f}$ & $1.0 \pm 0.03 \mathrm{~d}$ \\
\hline KO5428 & $0.7 \pm 0.01 \mathrm{f}$ & $0.7 \pm 0.01 \mathrm{~d}$ & $0.8 \pm 0.05 \mathrm{~d}$ & $0.9 \pm 0.03 \mathrm{f}$ & $1.0 \pm 0.02 \mathrm{~d}$ \\
\hline KO5427 & $0.7 \pm 0.10 \mathrm{f}$ & $0.7 \pm 0.02 \mathrm{~d}$ & $0.7 \pm 0.06 \mathrm{~d}$ & $0.9 \pm 0.05 \mathrm{f}$ & $1.0 \pm 0.03 \mathrm{~d}$ \\
\hline KO5426 & $1.5 \pm 0.06 \mathrm{~b}$ & $1.6 \pm 0.04 b$ & $1.9 \pm 0.14 \mathrm{a}$ & $1.7 \pm 0.03 \mathrm{bc}$ & $2.2 \pm 0.07 \mathrm{a}$ \\
\hline KO5425 & $1.2 \pm 0.05 \mathrm{~d}$ & $1.1 \pm 0.05 \mathrm{e}$ & $1.5 \pm 0.05 b c$ & $1.3 \pm 0.06 \mathrm{e}$ & $1.5 \pm 0.12 \mathrm{c}$ \\
\hline KO5424 & $1.5 \pm 0.05 b$ & $1.5 \pm 0.03 b$ & $1.5 \pm 0.10 \mathrm{bc}$ & $1.8 \pm 0.07 \mathrm{~b}$ & $2.2 \pm 0.08 \mathrm{a}$ \\
\hline KO5423 & $1.4 \pm 0.02 \mathrm{bc}$ & $1.4 \pm 0.03 \mathrm{bc}$ & $1.9 \pm 0.12 \mathrm{a}$ & $1.6 \pm 0.04 \mathrm{~cd}$ & $2.0 \pm 0.07 \mathrm{~b}$ \\
\hline KO5422 & $1.3 \pm 0.6 \mathrm{~cd}$ & $1.3 \pm 0.05 \mathrm{~cd}$ & $1.7 \pm 0.15 \mathrm{abc}$ & $1.5 \pm 0.04 \mathrm{~d}$ & $1.9 \pm 0.08 \mathrm{~b}$ \\
\hline KO5421 & $1.8 \pm 0.04 \mathrm{a}$ & $1.7 \pm 0.06 \mathrm{a}$ & $1.8 \pm 0.17 \mathrm{ab}$ & $2.0 \pm 0.04 \mathrm{a}$ & $2.4 \pm 0.09 \mathrm{a}$ \\
\hline \multicolumn{6}{|c|}{ Maturity group II } \\
\hline Vojvodjanka & $1.1 \pm 0.03 \mathrm{e}$ & $1.1 \pm 0.03 \mathrm{~g}$ & $1.0 \pm 0.02 \mathrm{~d}$ & $1.1 \pm 0.04 \mathrm{ef}$ & $1.1 \pm 0.05 \mathrm{e}$ \\
\hline KO5319 & $1.41 \pm 0.01 \mathrm{~d}$ & $1.4 \pm 0.02 \mathrm{def}$ & $1.2 \pm 0.06 \mathrm{~cd}$ & $1.3 \pm 0.03 \mathrm{de}$ & $1.4 \pm 0.01 \mathrm{cde}$ \\
\hline KO5318 & $1.4 \pm 0.07 \mathrm{~cd}$ & $1.4 \pm 0.04 \mathrm{cde}$ & $1.4 \pm 0.07 \mathrm{bc}$ & $1.5 \pm 0.04 \mathrm{~b}$ & $1.8 \pm 0.04 \mathrm{ab}$ \\
\hline KO5317 & $1.1 \pm 0.05 \mathrm{e}$ & $1.2 \pm 0.04 \mathrm{efg}$ & $1.3 \pm 0.08 \mathrm{bcd}$ & $1.3 \pm 0.04 \mathrm{~cd}$ & $1.5 \pm 0.04 \mathrm{bcd}$ \\
\hline KO5316 & $1.7 \pm 0.07 \mathrm{bc}$ & $1.7 \pm 0.10 \mathrm{ab}$ & $1.7 \pm 0.05 \mathrm{ab}$ & $1.4 \pm 0.10 \mathrm{bcd}$ & $1.7 \pm 0.12 \mathrm{abc}$ \\
\hline KO5315 & $1.1 \pm 0.01 \mathrm{e}$ & $1.1 \pm 0.04 \mathrm{fg}$ & $1.5 \pm 0.30 \mathrm{bc}$ & $1.1 \pm 0.03 \mathrm{f}$ & $1.3 \pm 0.03 \mathrm{de}$ \\
\hline KO5314 & $1.1 \pm 0.03 \mathrm{e}$ & $1.1 \pm 0.02 \mathrm{fg}$ & $1.0 \pm 0.02 \mathrm{~d}$ & $1.3 \pm 0.04 \mathrm{~cd}$ & $1.5 \pm 0.04 \mathrm{bcd}$ \\
\hline KO5313 & $1.7 \pm 0.16 \mathrm{~b}$ & $1.6 \pm 0.16 \mathrm{abc}$ & $1.7 \pm 0.13 \mathrm{~b}$ & $1.5 \pm 0.10 \mathrm{bc}$ & $1.9 \pm 0.23 \mathrm{a}$ \\
\hline KO5312 & $1.6 \pm 0.15 \mathrm{bcd}$ & $1.6 \pm 0.17 \mathrm{bcd}$ & $1.5 \pm 0.13 b c$ & $1.5 \pm 0.07 \mathrm{~b}$ & $1.7 \pm 0.06 \mathrm{abc}$ \\
\hline KO5311 & $2.0 \pm 0.05 \mathrm{a}$ & $1.9 \pm 0.04 \mathrm{a}$ & $2.0 \pm 0.15 \mathrm{a}$ & $1.9 \pm 0.06 \mathrm{a}$ & $1.8 \pm 0.21 \mathrm{ab}$ \\
\hline \multicolumn{6}{|c|}{ Maturity group III } \\
\hline Morava & $1.7 \pm 0.22 \mathrm{~cd}$ & $1.2 \pm 0.07 \mathrm{de}$ & $0.7 \pm 0.05 b$ & $1.3 \pm 0.07 \mathrm{a}$ & $1.3 \pm 0.03 \mathrm{~d}$ \\
\hline KO539 & $2.9 \pm 0.27 \mathrm{ab}$ & $1.9 \pm 0.09 \mathrm{abc}$ & $2.2 \pm 0.31 \mathrm{a}$ & $1.1 \pm 0.10 \mathrm{ab}$ & $1.3 \pm 0.06 \mathrm{~d}$ \\
\hline KO538 & $3.1 \pm 0.19 \mathrm{a}$ & $2.2 \pm 0.11 \mathrm{ab}$ & $2.1 \pm 0.27 \mathrm{a}$ & $1.2 \pm 0.10 \mathrm{ab}$ & $1.7 \pm 0.02 \mathrm{bc}$ \\
\hline KO537 & $2.7 \pm 0.17 \mathrm{ab}$ & $2.4 \pm 0.17 \mathrm{a}$ & $2.4 \pm 0.23 \mathrm{a}$ & $1.1 \pm 0.08 \mathrm{ab}$ & $1.7 \pm 0.08 \mathrm{abc}$ \\
\hline KO536 & $3.1 \pm 0.24 \mathrm{a}$ & $2.0 \pm 0.19 \mathrm{abc}$ & $1.6 \pm 0.34 \mathrm{a}$ & $0.9 \pm 0.09 b$ & $1.5 \pm 0.10 \mathrm{~cd}$ \\
\hline KO535 & $2.5 \pm 0.12 \mathrm{ab}$ & $2.2 \pm 0.13 \mathrm{ab}$ & $2.3 \pm 0.32 \mathrm{a}$ & $1.1 \pm 0.11 \mathrm{ab}$ & $1.7 \pm 0.04 \mathrm{bc}$ \\
\hline KO534 & $2.5 \pm 0.45 \mathrm{ab}$ & $1.6 \pm 0.23 \mathrm{~cd}$ & $2.0 \pm 0.41 \mathrm{a}$ & $1.0 \pm 0.09 \mathrm{ab}$ & $1.8 \pm 0.23 \mathrm{ab}$ \\
\hline KO533 & $2.3 \pm 0.20 \mathrm{bc}$ & $1.8 \pm 0.15 \mathrm{c}$ & $2.1 \pm 0.20 \mathrm{a}$ & $1.1 \pm 0.13 \mathrm{ab}$ & $1.8 \pm 0.05 \mathrm{abc}$ \\
\hline KO532 & $2.5 \pm 0.12 \mathrm{ab}$ & $1.8 \pm 0.10 \mathrm{bc}$ & $2.3 \pm 0.25 \mathrm{a}$ & $1.3 \pm 0.16 \mathrm{ab}$ & $2.0 \pm 0.08 \mathrm{a}$ \\
\hline KO531 & $1.5 \pm 0.06 \mathrm{~d}$ & $1.2 \pm 0.09 \mathrm{e}$ & $1.7 \pm 0.26 \mathrm{a}$ & $1.0 \pm 0.12 \mathrm{ab}$ & $1.5 \pm 0.12 \mathrm{~cd}$ \\
\hline
\end{tabular}

${ }^{(1)}$ Mean \pm standard errors followed by equal letters do not differ, at $5 \%$ probability. 
$\beta$-conglycinin than the Afrodita control cultivar. In maturity group I, there were significantly more $\alpha$ ' and $\alpha$ subunits of $\beta$-conglycinin than in the control in all genotypes, except for KO5427, KO5428, and KO5429, that had significantly less of those subunits. In maturity group II, there were also significantly more $\alpha^{\prime}$ and $\alpha$ subunits of $\beta$-conglycinin in KO5311, KO5313, KO5316, KO5312, KO5318, and KO5319 genotypes in comparison to the control. Morava, the control cultivar of maturity group III, had significantly lower content of $\alpha$ ' subunits compared with all tested genotypes, except for KO531 and KO533. It also had significantly lower content of $\alpha$ subunits except for genotypes KO531 and KO534. Comparing the $\beta$ subunits of $\beta$-conglycinin of high-protein soybean genotypes, of the maturity group 0 , to that of the Afrodita normal seed protein line, it was found that only genotypes KO5437 and KO5435 were significantly higher. In maturity group I, these subunits were significantly higher in all genotypes, except for KO5427, KO5428, and KO5429. Genotypes KO5311, KO5316, KO5313, KO5315, KO5312, and KO5318 contained noticeably more $\beta$ subunits of $\beta$-conglycinin than the control cultivar of maturity group II. In maturity group III, these subunits were significantly lower in the Morava control cultivar, when compared to all of the tested genotypes.

Glycinin acetic polypeptides were significantly higher in all tested genotypes, except for KO5431, $\mathrm{KO} 5434$, and KO5433 in maturity group 0. In maturity group I, genotypes KO5427, KO5428, and KO5429 contained significantly less acetic polypeptides, while genotypes KO5421, KO5424, KO5426, KO5423, and KO5422 contained significantly more of these subunits than the Balkan control cultivar. Genotypes KO5311, KO5318, KO5312, KO5413, KO5316, KO5317, and
KO5314 had significantly higher amounts of acidic polypeptides than the Vojvodjanka control cultivar of maturity group II. Only genotype KO536 from maturity group III differed significantly from the Morava control.

The basic glycinin polypeptides were significantly higher in all genotypes within maturity group 0 . Genotypes KO5427, KO5428, and KO5429 had significantly lower amount of acetic subunits, whereas genotypes KO5421, KO5424, KO5426, KO5423, and KO5422 in maturity group I had significantly higher contents. Only genotypes KO5319 and KO5315 from maturity group II and genotypes KO531, KO536, and KO539 did not differ significantly from the controls.

Significant correlations were found among all of the investigated subunits, except for the glycinin acidic subunit, and other protein subunits in maturity group III (Tables 3 and 4). Most of the subunits did not show significant correlations with protein content, except in maturity group I. Only the basic glycinin subunit showed weak significant correlation with the protein content across all the maturity groups. Fehr et al. (2003) observed no correlation between soybean protein subunits and protein content. This finding indicates that it is possible to select soybean genotypes for desired protein composition without influence on protein content. In maturity group 0 , all subunits were negatively correlated with yield in contrast to maturity group I, where none of subunits was correlated with yield. Except for maturity group I, $\beta$-subunits of $\beta$-conglycinin were negatively correlated with yield in all maturity groups.

Earlier studies showed that high-protein cultivars accumulated higher amounts of glycinin and $\beta$-conglycinin (Yaklich, 2001; Krishnan et al., 2007). This study confirmed this observation, except for genotypes KO5427,

Table 3. Estimates of phenotypic correlation coefficients among yield, protein and oil contents and protein subunits of soybean genotypes maturity group 0 (above diagonal) and maturity group I (below diagonal), at 5\% probability.

\begin{tabular}{lccccccccc}
\hline & Yield & Protein & Oil & Protein/oil & $\alpha$ s subunit & $\alpha$ subunit & $\beta$ subunit & Acidic & Basic \\
\hline Yield & & -0.64 & 0.61 & -0.63 & -0.42 & -0.53 & -0.43 & -0.62 & -0.56 \\
Protein & -0.48 & & -0.86 & 0.93 & ns & 0.26 & ns & 0.35 \\
Oil & 0.49 & -0.96 & & -0.98 & -0.26 & -0.28 & ns & -0.42 \\
Protein/oil & -0.47 & 0.98 & -0.99 & & ns & ns & ns & 0.35 & ns \\
$\alpha$ subunit & ns & -0.34 & 0.3 & -0.35 & & 0.82 & 0.67 & 0.57 & 0.77 \\
$\alpha$ subunit & ns & -0.38 & 0.34 & -0.39 & 0.98 & & 0.67 & 0.67 & 0.76 \\
$\beta$ subunit & ns & -0.31 & ns & -0.31 & 0.89 & 0.92 & & 0.69 & 0.50 \\
Acidic & ns & -0.38 & 0.38 & -0.41 & 0.92 & 0.91 & 0.76 & 0.98 & 0.94 \\
Basic & ns & -0.37 & 0.34 & -0.39 & 0.96 & 0.96 & 0.88 & 0.50 \\
\hline
\end{tabular}

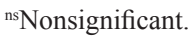


KO5428, and KO5429, which accumulated smaller amounts of all subunits of glycinin and $\beta$-conglycinin, in comparison to the controls. However, according to the protein content, these genotypes occupied first, sixth, and second place, respectively. This can be the reason why the correlation between protein content and presence of subunits was found to be negative.

Principal factor analyses identified two principal components in maturity groups 0 , I and II and three in maturity group III (Figure 2). The first two principal components explain between 72 and $88 \%$ of the total variation. All protein subunits were separated by factorial analysis and put aside. Protein content and protein/oil ratio are on the opposite side of yield and oil content on the loading plot, due to their mutual y inverse relationships. No differences between protein subunits in maturity groups 0 , I and II were observed. In maturity group III, the acidic subunit was separated from other subunits, and this variation was explained by the third principal component. Expression of acidic subunit of glycinin in high protein genotypes of maturity group III was low, and there was no enhancement of this subunit in comparison to the Morava control cultivar. Principal factor analysis pointed out the interrelationships between yield, protein, oil content, and protein structure and showed the independence of protein subunit content from the other analyzed traits.

Knowledge on subunit production could significantly affect the quality of protein stored in the soybean seed (Yaklich, 2001). Glycinin is a better source of sulphur amino acids than $\beta$-conglycinin. The subunits of glycinin in the tested genotypes were expressed differently, indicating that some of them could be used in selection for cultivars with desirable amino acid composition. Attention should be paid to genotypes KO5314 and KO5317, which accumulated significantly higher quantity of both glycinin subunits (basic and acidic) with no significant influence on $\beta$-conglycinin. In contrast, genotypes KO5425, KO5319 and KO539 accumulated higher amounts of $\beta$-conglycinin subunits with no significant differences on glycinin subunits, and KO536 with significant lower glycinin acetic polypeptides. As reported by Pesic et al. (2005), the level of $\beta$-conglycinin had a positive influence on protein extractability. Having this in mind, these genotypes can be used in soybean breeding for the food industry, where greater extractability of protein is needed. It is also important to find a balance between farmers' demand for high yielding varieties with the demand of the processing industry for enhanced protein content and specific protein composition.

Thus, some genotypes can be selected for future research. Genotype KO5316 has a yield similar to control cultivar Vojvodjanka with higher protein content (approximately $50 \mathrm{~g} \mathrm{~kg}^{-1}$ ). Although the yields of genotypes KO5426, KO5424, KO5423 and KO5422 were not significantly different from Balkan, their protein content was about $20 \mathrm{~g} \mathrm{~kg}^{-1}$ higher. An increased protein content in these genotypes was due to enhanced glycinin and $\beta$-conglycinin subunits. In maturity group III, genotypes KO537, KO538 and KO539 were not significantly different in yield from the Morava control, but their protein content was $40-50 \mathrm{~g} \mathrm{~kg}^{-1}$ higher. Increase in protein content in the KO537 and KO538 genotypes were due to enhanced $\beta$-conglycinin and basic subunits of glycinin. Genotype KO539 accumulates significantly more $\beta$-conglycinin than Morava, with no influence on glycinin content.

Table 4. Estimates of phenotypic correlation coefficients among yield, protein and oil contents and protein subunits of soybean genotypes maturity group II (above diagonal) and maturity group III (below diagonal) at 5\% probability.

\begin{tabular}{|c|c|c|c|c|c|c|c|c|c|}
\hline & Yield & Protein & Oil & Protein/oil & $\alpha^{\prime}$ subunit & $\alpha$ subunit & $\beta$ subunit & Acidic & Basic \\
\hline Yield & & -0.36 & 0.4 & -0.36 & ns & ns & -0.36 & ns & ns \\
\hline Protein & -0.48 & & -0.92 & 0.95 & ns & ns & ns & ns & 0.26 \\
\hline Oil & 0.51 & -0.97 & & -0.99 & ns & ns & -0.28 & -0.27 & -0.28 \\
\hline Protein/oil & -0.47 & 0.98 & -0.99 & & ns & ns & ns & ns & ns \\
\hline$\alpha^{`}$ subunit & ns & ns & ns & ns & & 0.86 & 0.63 & 0.75 & 0.64 \\
\hline$\alpha$ subunit & -0.32 & ns & ns & ns & 0.77 & & 0.73 & 0.80 & 0.74 \\
\hline$\beta$ subunit & -0.64 & 0.31 & -0.33 & 0.26 & 0.43 & 0.72 & & 0.62 & 0.60 \\
\hline Acidic & ns & ns & ns & ns & ns & ns & ns & & 0.79 \\
\hline Basic & -0.46 & 0.34 & -0.39 & 0.35 & 0.41 & 0.50 & 0.71 & ns & \\
\hline
\end{tabular}

${ }^{n}$ Nonsignificant. 

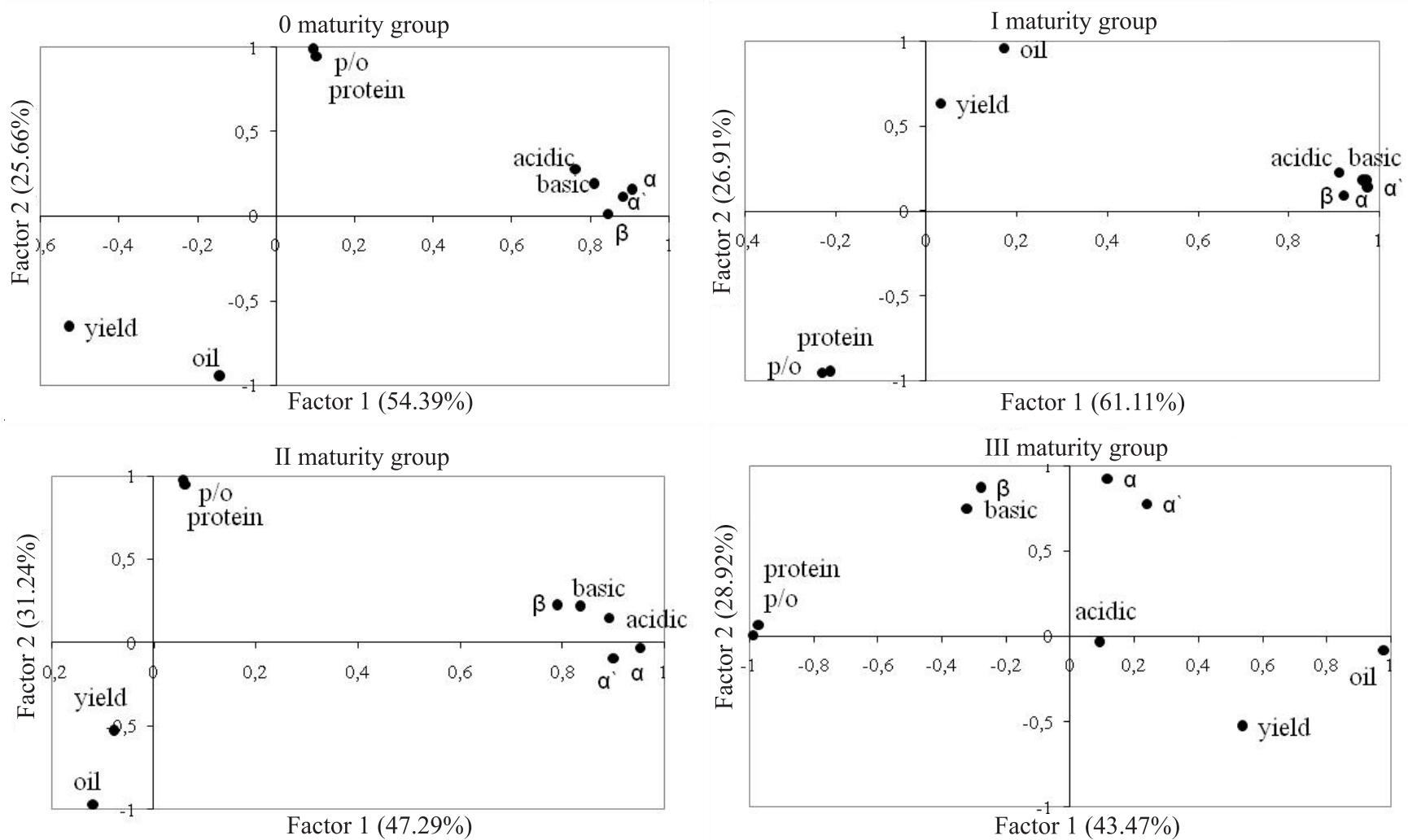

Figure 2. Loading plots of the two first dimensions of principal factor analysis of yield, protein and oil content and ratio and protein subunits.

\section{Conclusions}

1. High-protein cultivars generally accumulate higher amounts of glycinin and $\beta$-conglycinin.

2. Accumulation of a significantly higher quantity of glycinin subunits, with no significant influence on $\beta$-conglycinin, in genotypes KO5314 and KO5317, may be beneficial in selection for cultivars with desirable amino acid composition.

3. Accumulation of higher amounts of subunits of $\beta$-conglycinin, in KO5425, KO5319, KO539 and KO536, can be used in soybean breeding for the food industry, where greater extractability of protein is needed.

4. Genotypes KO5426, KO5424, KO5423, KO5422, KO5316, KO537, KO538 and KO539, which have a similar yield to the control for their respective maturity group, can be used in the production of high yielding varieties with enhanced protein content.

5. Protein subunit content is independent of yield, oil and protein content, making it possible to carry out soybean breeding for specific protein composition with desirable agronomic characteristics.

\section{Acknowledgements}

To the Serbian Ministry of Science and Technological Development, for support; to MSc. Bojana Stanic for densitometric analysis; and to Dr. Nevena Nagl for critical review of the manuscript.

\section{References}

BRADFORD, M.M. A rapid and sensitive method for the quantitation of microgram quantities of protein utilizing the principle of protein-dye binding. Analytical Biochemistry, v.72, p.248-254, 1976.

BRUMM, T.J.; HURBURGH JUNIOR, C.R. Quality of the 2002 soybean crop from the United States. In: ANNUAL REPORT of the AMERICAN SOYBEAN ASSOCIATION, 2002, St. Louis. Proceedings. St. Louis: American Soybean Association, 2002. p.1-14.

BURTON, J.W. Quantitative genetics: results relevant to soybean breeding. In: WILCOX, J.R. (Ed.). Soybeans: improvement, production and uses. Madison: American Society of Agronomy, 1987. p.211-247.

COBER, E.R.; VOLDENG, H.D. Developing high-protein, high-yield soybean populations and lines. Crop Science, v.40, p.39-42, 2000. 
FEHR, W.R.; HOECK, J.A.; JOHNSON, S.L.; MURPHY, P.; NOTT, J.D.; PADILlA, G.; WELKE, G. Genotype and environment influence on protein components of soybean. Crop Science, v.43, p.511-514, 2003.

HELMS, T.C.; ORF, J.H. Protein, oil, and yield of soybean lines selected for increased protein. Crop Science, v.38, p.707-711, 1998.

KRISHNAN, H.B. Biochemistry and molecular biology of soybean seed storage proteins. Journal of New Seeds, v.2, p. 1-25, 2001.

KRISHNAN, H.B.; SAVITHIRY, S.N.; AHMED, A.M.; RANDALL, L.N. Identification of Glycinin and $\beta$-conglycinin subunits that contribute to the increased protein content of high-protein soybean lines. Journal of Agricultural and Food Chemistry, v.55, p.1839-1845, 2007.

LAEMMLI, U.K. Cleavage of structural proteins during assembly of head of bacteriophage T4. Nature, v.227, p.680-685, 1970.

MORI, T.; UTSUMI, S.; INABA, H.; KITAMURA, K.; HARADA, $K$. Differences in subunit composition of glycinin among soybean cultivars. Journal of Agricultural and Food Chemistry, v.29, p.20-23, 1981.

PESIC, M.B.; VUCELIC-RADOVIC, B.V.; BARAC, M.B.; STANOJEVIC, S.P. The influence of genotypic variation in protein composition of emulsifying properties of soy proteins. Journal of the American Oil Chemists Society, v.82, p.667-672, 2005.
POYSA, V.; WOODROW, L.; YU, K. Effect of soy protein subunit composition on tofu quality. Food Research International, v.39, p.309-317, 2006.

RASBAND, W.S. ImageJ. Available at: <http://rsb.info.nih.gov/ ij/>. Accessed on: 5 Aug. 2010.

STATSOFT. Statistica: data analysis software system. Version 8. Available at: $<$ http://www.statsoft.com/ >. Accessed on: 5 Aug. 2010.

TASKI-AJDUKOVIC, K.; DJORDJEVIC, V.; VIDIC, M.; VUJAKOVIC, M.; MILOŠEVIĆ, M.; MILADINOVIC, J. The main seed storage proteins among high-protein genotypes. Genetika, v.40, p.9-16, 2008.

THANH, V.H.; SHIBASAKI, K. Major proteins of soybean seeds. Subunit structure of $\beta$-conglycinin. Journal of Agricultural and Food Chemistry, v.26, p.692-695, 1978.

WILCOX, J.R. Sixty years of improvement in publicly developed elite soybean lines. Crop Science, v.41, p.1711-1716, 2001.

YAKLICH, R.W. $\beta$-Conglycinin and glycinin in high-protein soybean seeds. Journal of Agricultural and Food Chemistry, v.49, p.729-735, 2001.

ZARKADAS, C.G.; GAGNON, C.; GLEDDIE, S.; KHANIZADEH, S.; COBER, E.R.; GUILLEMETTE, R.J.D. Assessment of the protein quality of fourteen soybean [Glycine max (L.) Merr.] cultivars using amino acid analysis and two-dimensional electrophoresis. Food Research International, v.40, p.129-146, 2007. 